\title{
O CURRÍCULO NARRATIVO NA EDUCAÇÃO INFANTIL DAS CRIANÇAS DO CAMPO: REFLEXÕES PARA UM DIÁLOGO PEDAGÓGICO
}

\author{
Jaqueline Pasuch ${ }^{1}$ \\ Cléria Paula Franco ${ }^{I}$
}

RESUMO: Neste ensaio, aproximamos as concepçóes de currículo narrativo e educaçáo infantil do campo para propor um diálogo pedagógico em torno dos bebês e das crianças pequenas residentes em áreas rurais do Brasil. O desafio está no complexo atendimento às crianças do campo, face à sua diversidade, bem como de práticas pedagógicas. Questionamo-nos a respeito da constituição de um currículo narrativo, articulador de saberes e fazeres das crianças, organicamente vinculado aos modos de ser/estar e produzir a vida no campo.

Palavras-chave: Educação infantil do campo. Currículo narrativo. Diálogo pedagógico.

\section{The narrative curriculum in rural childhood education: reflections for a pedagogical dialogue}

ABSTRACT: In this essay we approximate the conceptions of narrative curriculum and children's education in the countryside to propose a pedagogical dialogue about infants and young children

${ }^{1}$ Universidade do Estado de Mato Grosso - Cáceres (MT), Brasil. E-mails: jaqueline.pasuch@gmail.com; cleria_franco@outlook.com DOI: $10.1590 / C C 0101-32622017176082$ 
living in rural areas of Brazil. The challenge is the complex care given to the diversity of the rural children and the pedagogical practices. We inquire about the constitution of a narrative curriculum, articulator of children's knowledge and actions, organically linked to the ways of being and producing life in the field.

Keywords: Rural childhood education. Narrative curriculum. Pedagogical dialogue.

\section{INTRODUÇÃO}

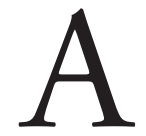

$s$ reflexões aqui apresentadas são provenientes do entrelaçamento de estudos realizados no Grupo de Pesquisa Educação e Diversidade no Contexto da Amazônia Legal Matrogrossense (Universidade do Estado do Mato Grosso - UNEMAT/Conselho Nacional de Desenvolvimento Científico e Tecnológico - CNPq) no âmbito do projeto de pesquisa "Infâncias na Diversidade", complementadas na pesquisa de Mestrado em Educação "A escola da criança feliz: significaçôes da educação infantil do/no campo", de Cléria Paula Franco, orientada por Jaqueline Pasuch (FRANCO, 2016). Neste artigo, exploramos parte do material empírico da pesquisa de Mestrado, realizada no período de 2014 e 2015, que teve como objetivo compreender as significações da educaçáo infantil do/no campo para os sujeitos integrantes de uma escola localizada em uma comunidade rural, distante $35 \mathrm{~km}$ do Centro de Nova Mutum ${ }^{1}$, região médio-norte do Estado de Mato Grosso. Situada em um espaço de latifúndios, grandes fazendas produtoras do agronegócio, a escola campo de pesquisa atende às crianças moradoras do seu entorno, filhas de fazendeiros, trabalhadores rurais e de um assentamento de reforma agrária composto por pequenos agricultores familiares.

A perspectiva teórico-metodológica "Rede de Significaçôes" (ROSSETTI-FERREIRA et al., 2004) fundamentou a realização da pesquisa que envolveu: observação participante; registros fotográficos; análise do Projeto Político Pedagógico Escolar; entrevistas com 
37 pessoas, sujeitos da pesquisa, sendo 16 crianças de 4 a 6 anos de idade, 12 adultos, subdivididos entre profissionais da escola (diretora, professora e coordenadora) e profissionais que se relacionam diretamente com as crianças da turma de educação infantil (motorista, monitora e instrutor de projetos), 5 famílias, 2 membros do movimento sindical, 1 morador da comunidade e 1 representante da gestão educacional da rede municipal.

As crianças e as professoras da turma de educação infantil, a partir de suas experiências concretas de vivências em contextos antagônicos - agronegócio versus agricultura familiar —, constroem relaçóes cotidianas respeitosas e acolhedoras das realidades diferenciadas. As crianças moradoras das proximidades da escola deslocam-se a pé de suas residências, já as crianças filhas de proprietários e de trabalhadores das fazendas latifundiárias, assim como as crianças residentes em assentamento rural ${ }^{2}$, fazem uso do transporte escolar. A professora da turma é residente na vila onde se localiza a escola, assim como as demais docentes, profissionais de apoio e equipe de gestão escolar. É uma escola considerada "escola do campo e no campo" porque integra em sua filosofia os princípios político-pedagógicos construídos pelo projeto de Educação do/no Campo (CALDART, 2004; ARROYO, 2004).

A temática de estudo "currículo da educação infantil das crianças do campo" representa uma novidade para a área educacional, pois tanto os estudos e as pesquisas referentes à educação do campo quanto os de educação infantil nem sempre aprofundaram especificamente a questão curricular, tal como concebida nas Diretrizes Curriculares Nacionais da Educação Infantil - DCNEI (BRASIL, 2009) e vivenciada pelas crianças residentes em áreas rurais, em suas especificidades e diversidades social, cultural, geográfica e populacional. Refletir sobre essa temática não é uma tarefa fácil, pois envolve a definição conceitual de currículo, educação infantil, crianças do campo, assim como o enfrentamento de dilemas teóricos e tensões políticas em campos de conhecimento, pesquisas e práticas pedagógicas. Este trabalho que teremos é desafiador e, ao mesmo tempo, fundamental, pois coloca no centro do debate o currículo na constituição da proposta político-pedagógica escolar. 


\section{A EDUCAÇÃO INFANTIL DAS CRIANÇAS DO CAMPO: APROXIMANDO CONCEITOS E CONTEXTOS}

A oferta da educação infantil com qualidade para as crianças residentes em áreas rurais constitui-se como um dos grandes desafios da educação brasileira. A distribuição desigual das políticas públicas e a dificuldade de acesso à matrícula foram constatadas na pesquisa nacional "Caracterização das Práticas Educativas com crianças de 0 a 6 anos residentes em áreas rurais", realizada em $2010^{3}$ por meio de um acordo de cooperação técnica entre o Ministério da Educação (MEC) e a Universidade Federal do Rio Grande do Sul (UFRGS). O Censo Demográfico de 2010 mostra que 3.546 milhóes de crianças de até 6 anos são residentes em áreas rurais e que a distribuição da população infantil de 0 a 6 anos não é semelhante em todo o território nacional, pois $50 \%$ das crianças vivem na Regiấo Nordeste do país e 5\% na Região Centro-Oeste, o que significa uma grande disparidade e a necessidade de atenção redobrada na perspectiva da proposição de políticas públicas (BRASIL, 2012).

De acordo com os resultados quantitativos da referida pesquisa, no universo de crianças de 0 a 6 anos residentes em áreas rurais, $12,1 \%$ frequentam creches e $67,6 \%$ frequentam pré-escolas, um valor inferior ao das áreas urbanas, onde a cobertura é de $26 \%$ de frequência para a creche e de $83 \%$ em turmas de pré-escola. O Censo Escolar do Instituto Nacional de Estudos e Pesquisas Anísio Teixeira (INEP) de 2010 demonstra que a oferta de vagas em educação infantil é realizada, principalmente, em escolas situadas nas áreas urbanas e para as crianças de mais de quatro anos. (BARBOSA, 2012).

Silva et al. (2012) afirmam que a oferta de educação infantil começou a ganhar um pouco mais de consistência com os vários documentos e legislaçóes que alertam e orientam para a superação dessa realidade e para a obrigatoriedade da educação infantil, os quais vêm sendo publicados, problematizando e chamando a atenção para com os povos do campo. Para as autoras:

Durante muito tempo, as políticas educacionais não reconheceram os povos do campo como produtores 
de conhecimento. Nas suas diversidades, os povos da floresta, caiçaras, ribeirinhos, assentados, povos dos interiores eram vistos como meros receptores de propostas elaboradas numa lógica que os submetia a relaçôes de dominação sob os aspectos culturais, ambientais, econômicos, políticos. Nas últimas décadas, uma nova concepção ganha força, gestada pelos próprios sujeitos do campo, organizados nos movimentos sociais de luta pela democratização da terra, preservação das matas e florestas, rios, manguezais e reconhecimento das culturas. Essa concepção é denominada Educação do Campo (SILVA et al., 2012, p. 1).

A grande preocupação das autoras, demais pensadores, gestores e profissionais da área refere-se à educação específica para as crianças do campo no próprio campo, pois, geralmente, as práticas pedagógicas são desenvolvidas a partir de um currículo urbano e, quase sempre, deslocadas das necessidades e da realidade do mesmo. Ou seja, muitas propostas educacionais destinadas às populaçóes do campo tratam de uma educação forjada fora do espaço de produção da vida das pessoas, não respeitando as especificidades culturais do meio rural. Conforme Silva e Pasuch (2010, p. 3):

A criança do campo constrói sua identidade e autoestima na relação com o espaço em que vive, com sua cultura, com os adultos e as crianças de seu grupo. Ela constrói amizades, compartilha com outras crianças segredos e regras. Brinca de faz-de-conta, pula, corre, fala e narra suas experiências, conta com alegria e emoção as grandes e pequenas maravilhas no encontro com o mundo.

As especificidades da educação infantil das crianças do campo se inserem num movimento amplo de lutas por uma educação que reconheça a participação desses sujeitos (crianças e povos dos territórios rurais) no processo de construção do conhecimento do mundo e de si mesmos; tal como já se tem avançado no que se refere aos con- 
textos urbanos, é necessário considerar que essa etapa da educação é direito das crianças e não apenas das famílias trabalhadoras. Dessa forma, consideramos importante reafirmar que a educação infantil a ser construída para as crianças do campo deve reconhecer que elas (re) produzem cultura e, assim, participam dos processos de construção dos conhecimentos, tanto daqueles específicos dos contextos em que vivem quanto da sociedade como um todo. As formas de produção de conhecimentos têm muito em comum com as que se referem ao conjunto das crianças brasileiras, mas expressam também o que é próprio da relação com a natureza, com os adultos, com os condicionantes que estruturam o campo brasileiro e as vivências de seus sujeitos, com os artefatos disponíveis em seus contextos de vida e, evidentemente, as relaçóes que estabelecem entre si.

\section{O CURRÍCULO COMO MODO DE CONSTRUÇÃO NARRATIVA DA EXPERIÊNCIA DE APRENDIZAGEM DAS CRIANÇAS DO CAMPO}

As DCNEI apontam para a possibilidade de consideração de um currículo narrativo quando o consideram como:

[...] a articulação das experiências e os saberes das crianças com os conhecimentos que fazem parte do patrimônio cultural, artístico, científico e tecnológico da sociedade por meio de práticas planejadas e permanentemente avaliadas que estruturam o cotidiano das instituiçôes (BRASIL, 2009, p. 3).

Nessa perspectiva, Goodson (2008, p. 152) define currículo narrativo como um processo, um percurso a ser realizado por um grupo de professores e estudantes no contexto escolar. $\mathrm{O}$ autor explicita que o "aprendizado narrativo ocorre durante a elaboraçáo e a manutençáo contínua de uma narrativa de vida”. Assim, ele estará vinculado ao engajamento e à compreensão das crianças sobre o mundo, envolvido com os entusiasmos de cada uma delas e ancorado em seus percursos 
de vida. A ação docente na educação infantil centraliza-se na observação, contextualização, articulação dos conhecimentos formais com os saberes das crianças e apoia as indagaçóes e investigaçóes infantis. Goodson nos auxilia na mudança de concepção de aprendizagem como aquisição para uma concepção de aprendizagem como construção narrativa da experiência, como histórias de aprendizagens de crianças e adultos, grupos e instituiçóes. O currículo deixa de ser um caminho linear, previamente definido e avaliado em seu produto final, e passa a ser constituído pelos diferentes percursos narrativos das experiências que acontecem no encontro cotidiano entre estudantes e professores nos espaços escolares.

Passaremos a destacar narrativas desenvolvidas durante a pesquisa de Mestrado, no acompanhamento da turma de educação infantil referida anteriormente. O primeiro diálogo demonstra o conhecimento que as crianças possuem sobre o mundo em que vivem, a natureza e seu contexto.

Júnior: Professora? Olha, encontrei uma pena de galinha! Bia: Não é de galinha, é de papagaio.

Paulo: Não é de papagaio, não! De papagaio não é dessa cor!

Lorena: De papagaio é verde!

Pesquisadora: Então é de quê, afinal?

Bia: Deve ser de gaviáo. Sabia que ele pega pintinho?

Paulo: E ele come rato e cobra também. Um dia lá perto do silo um gavião pegou um rato e saiu voando com ele no bico.

Júnior: Se essa pena não for de gavião deve ser de outro pássaro.

Paulo: $\mathrm{O}$ gaviáo fica lá do alto olhando as presas e quando ele vê: inhac! [Gesticula com a mão a forma como o gaviáo agarra sua presa].

Júnior presenteia a pesquisadora com a pena encontrada. (FRANCO, Diário de Campo, 13/03/2015).

Além de espécies diferentes, elas narram também o tipo de alimentação que uma determinada ave costuma ter e a forma como age para 
pegar sua presa. Esses saberes compóem o cotidiano da vida das crianças do campo de uma forma bastante comum, natural para elas, e são bastante representativos do modo como se relacionam com as experiências vividas.

A próxima narrativa ocorreu na escola, um pouco antes do horário do almoço, quando a professora propôs atividades livres no pátio. Percebemos que um grupo de crianças $^{4}$ se aproximou de uma árvore e começou a tocar em seu caule:

Pesquisadora: $\mathrm{O}$ que vocês estáo fazendo?

Júnior: Descascando ela, ué! [se referindo à árvore]

Pesquisadora: Será que vocês não vão machucá-la?

Júnior: Não machuca, não. As cascas já estão secas e elas vão cair.

Lorena: Sabia que aqui no pomar da escola tem uma árvore chamada orelha de macaco?

Pesquisadora: Verdade, Lorena? Você pode me mostrar? [As crianças afirmam o que Lorena disse e me levam até o pomar da escola para que eu possa conhecer a árvore.]

Lorena: Esta árvore, aqui óóó.

Pesquisadora: E por que ela é chamada "orelha de macaco"?

Lorena: Ela tem esse nome porque tem umas coisinhas no tronco que parece uma orelha de macaco. Ainda está pequena, mas ela cresce viu? $\mathrm{Na}$ fazenda tem um monte, não pode cortar, meu pai falou que é reserva da floresta.

Bia: Lá tem outra árvore. É um pé de caju. Na minha casa tem um monte. Ele dá os cajus, minha avó faz doce pra gente comer. Mas os passarinhos comem tudo às vezes, os tucanos gostam de comer caju. (FRANCO, Diário de Campo 03/04/2015, folha 39).

Ao relatar que a escola possui uma árvore com nome "orelha de macaco", Lorena fez emergir saberes acerca de plantas nativas, sobre suas características e ainda faz relação com o tamanho, destacando que aquela está pequena, mas que pode crescer.

Além disso, há um conhecimento construído no cotidiano familiar de que não pode cortá-la porque é "reserva da floresta", ou seja, 
faz parte da reserva legal que deve ser preservada. Bia, ao falar sobre o pé de caju, demonstra o conhecimento que possui sobre a planta, suas funçôes no alimento da família e na vida dos animais, fala do lugar onde vive. Esses processos de vida relacionados a elementos da natureza são compreendidos pelas crianças porque fazem parte do cotidiano e exercem impacto no modo como expressam certas preocupaçóes, como na fala de Lorena ao dizer que não pode cortar porque é da reserva. Com isso, as crianças atribuem sentidos a elementos que fazem parte de seus contextos de vida e que as práticas pedagógicas precisam reconhecer como importantes saberes a serem considerados e aprofundados nas experiências de aprendizagens.

Vejamos no diálogo a seguir como a comercialização de produtos faz parte da vida familiar de quem vive no campo. As famílias do assentamento, por exemplo, produzem legumes e frutas para a venda tanto na feira como em alguns comércios de Nova Mutum e da cidade vizinha, Lucas do Rio Verde.

Bia: Quem quer comprar frutas da minha colheita? Pesquisadora: $\mathrm{O}$ que vocês estão vendendo?

Bia: Estamos vendendo abacaxi, melancia e limáo. Pesquisadora: Nossa! Que legal! Eu adoro abacaxi! De onde são estas frutas?

Bia: Lá do assentamento, minha vó que planta e a gente está aqui vendendo. Quer comprar?

Pesquisadora: Quanto custa o abacaxi?

Bia: Hum... Quanto é o abacaxi Lívia?

Lívia: É dez reais.

Pesquisadora: Nossa! Está muito caro. Faz um desconto pra mim?

Bia: Tá bom, a gente faz por um real, mas você tem que levar todos porque náo queremos voltar pra casa com eles.

Pesquisadora: Tudo bem. Entáo eu compro todos. (FRANCO, Diário de Campo, 26/03/2015, folha 18).

$\mathrm{Na}$ cena da brincadeira infantil "a venda de frutas", percebe-se uma reinterpretação do universo no qual as crianças convivem. As brincadeiras são criadas e recriadas por elas de diversas formas no 
ambiente escolar e são nesses momentos que as experiências dos contextos sociais são reinterpretadas pelas crianças a partir de suas vivências e participação no mundo.

Também ao convidar as crianças para brincarem com quebra-cabeças e peças de encaixes, em uma das açóes propostas pela professora da turma de educação infantil pesquisada, destacamos o seguinte diálogo:

Pesquisadora: $\mathrm{O}$ que vocês montaram?

Júnior: Eu montei um caminhão que está carregado de soja.

Pesquisadora: E o seu Paulo, o que é?

Paulo: Uma parruda, ué!

Pesquisadora: Uma parruda! O que é uma parruda?

Paulo: Você não sabe? É o trator que passa veneno na soja! Ela tem esses braços aqui bem grandes que daqui sai o veneno para passar. Ele vai andando e o veneno vai saindo daqui de baixo assim: "tsssssss" e espalha no meio da soja, a roda dele, tia, é bem alta assim [gestos].

Pesquisadora: Nossa, Paulo! Mas o veneno não é perigoso? Paulo: É nada! Ele só mata os "bicharedo" que comem a soja. Se não passar, a soja morre porque as lagartas acabam com tudo.

Pesquisadora: Quem passa o veneno nesta parruda? Paulo: Meu pai que passa e ele colhe a soja também na colheitadeira da Jhon Deere. Ela é bem grandona e vai rolando assim [gestos] e colhe a soja, depois que vai para o caminhão.

Pesquisadora: E o seu caminhão Júnior, vai pra onde com essa soja?

Júnior: Ele vai lá para o armazém da [nome de uma empresa do agronegócio] ${ }^{5}$, meu avô que leva.

Pesquisadora: A soja é do seu avô Júnior?

Júnior: Não, a soja é do dono da fazenda, ele só dirige o caminhão.

(FRANCO, narrativa videogravada em 27/03/2015).

As crianças estão situadas em um contexto histórico e social imbuído de valores, significados e atividades partilhadas com, 
entre e pelos sujeitos que ali vivem. Elas recriam esses elementos de um modo próprio, por meio das brincadeiras. Há um modo social, econômico, político e cultural atualizado no aqui agora da brincadeira infantil que, nesse caso específico, denuncia a sociedade em seus processos produtivos. $\mathrm{O}$ campo onde essas crianças vivem é composto por elementos que permitem relaçóes constantes com os saberes e dão significados às infâncias.

Nesse sentido, compartilhamos com Arendt a concepção de mundo comum como "aquilo que adentramos ao nascer e que deixamos para trás quando morremos”. É o que temos em comum "não só com aqueles que vivem conosco, mas também com aqueles que aqui estiveram antes e com aqueles que virão depois de nós". Com essa reflexáo, a autora indaga qual é o mundo que estamos preparando para acolher as crianças, os "recém-chegados", aqueles que trazem as novidades ao mundo existente antes delas nascerem (ARENDT, 2014, p. 68).

O recorte a seguir traz outra situação em que as crianças reinterpretam o universo de pertencimento.

Paulo: Profe, eu quero o quebra-cabeças da fazendinha! [Os demais meninos também manifestam preferência pelo mesmo escolhido por Paulo e os três passam a montar coletivamente o quebra-cabeças. As meninas pegam o das princesas].

Pesquisadora: Por que vocês gostam deste? Tem outras histórias também.

Paulo: Eu gosto desse aqui porque a gente monta a fazendinha. Tem o trator, o caminhão, a lavoura. Daí o homem pega o trator e vai para a lavoura, né, Bruno? Bruno: Tem os porquinhos aqui também e as vacas. Vem, Augusto, montar nossa fazendinha?

Pesquisadora: Podem contar a história desse cenário? Paulo: Tinha uma fazenda bem longe da cidade. O fazendeiro construiu a casa, o barracáo e uma represa. Na fazenda tinha um trator, um caminháo e uma camionete.

Bruno: Daí o homem pegava o trator todos os dias de manhá para gradear a terra e preparar para plantar.

Pesquisadora: $\mathrm{O}$ que o fazendeiro planta?

Bruno: Soja e milho.

Paulo: Deixa eu falar. O fazendeiro tinha dez vacas e 
cinco porquinhos no chiqueiro.

Pesquisadora: $\mathrm{O}$ que mais tem nesta fazenda?

Paulo: Tem o galinheiro também. As galinhas botam ovos, mas de noite elas têm medo porque o "lobete" vem pra pegar os filhotes dela. $\mathrm{O}$ fazendeiro faz armadilhas para pegar o "lobete" mas ele é esperto e foge.

Pesquisadora: Nossa, Paulo! Você já viu algum "lobete"? Paulo: Eu já. Lá na fazenda tem um monte. Eles aparecem só à noite para caçar.

Bruno: A fazenda era chamada de "Fazenda bonita" e o fazendeiro morava muito feliz com sua família e os animais. Fim!

(FRANCO, Diário de Campo 03/04/2015, folhas 38 e 39).

A narrativa demonstra o interesse das meninas em escolher o quebra-cabeça de princesas e dos meninos por um determinado quebra-cabeça, demonstrando o que melhor representa o contexto no qual eles vivem diariamente: o cenário rural, de uma fazenda com trator, plantaçóes e animais. Elementos que compóem o cotidiano dos meninos são evidenciados nessa situação, demonstrando a apropriação de elementos que fazem parte do dia a dia do trabalho de suas famílias. Ainda nessa cena, apresentam o conhecimento que possuem em relação à criação de animais domésticos e à existência de animais selvagens nas fazendas.

Caldart (2004) assinala que a educação é um processo social no qual se destacam a relação entre educação e vida produtiva, entre a formação humana e a cultura e entre a educação e a história. Nesse sentido, não é possível compreender a educação do campo fora desse entrelaçamento sócio-histórico e cultural, ou seja, fora das realidades das pessoas que vivem no e do campo.

Silva e Pasuch (2010) convidam-nos a refletir sobre as rotinas das crianças do campo, as experiências e vivências próprias, seus tempos e espaços construídos numa dinâmica que é específica do contexto rural:

As crianças do campo têm rotinas, experiências estéticas e éticas, ambientais, políticas, sensoriais, afetivas e sociais próprias. Os tempos de plantar e de colher, 
os ciclos de produção, de vida e de morte, o tempo das águas e estiagem, as aves e bichos do mato, dos mangues, dos pantanais, a época de reproduçáa dos peixes, aves, pássaros e outros animais, o amanhecer e o entardecer, o tempo de se relacionar com os adultos e crianças, tudo isso marca possibilidades diferenciadas de viver a infância, na multiplicidade que o campo brasileiro se configura (SILVA; PASUCH, 2010, p. 1).

Nesse sentido, na especificidade da educação infantil das crianças do campo, é preciso que se considerem os modos de ser e viver dos bebês e das crianças pequenas de maneira vinculada à organicidade de seus mundos de pertencimento, mas ao mesmo tempo, que se considere que suas comunidades, de alguma forma, também são afetadas pelos processos de urbanização que extrapolam os limites da cidade. Também as questôes estruturais de acesso à educação infantil relativas à locomoção, alimentação, espaços internos e externos, brinquedos e demais materiais e utensílios pedagógicos precisam ser consideradas nessa dupla dimensão, em que a oferta necessita pensar naquilo que é direito de todos os bebês e crianças pequenas (como segurança, conforto, alimentaçáo equilibrada, desafios para a aprendizagem significativa, entre muitos outros) e nas especificidades, dificuldades e modos próprios circunscritos pelos seus contextos de vida.

\section{REFLEXÕES FINAIS}

Considerando a necessidade de se consolidar uma política de educação infantil de qualidade que respeite os direitos fundamentais das crianças do campo, com especificidades próprias à fase de desenvolvimento infantil, torna-se necessário o estabelecimento de um diálogo pedagógico a respeito dos elementos que compóem o currículo escolar, tendo em vista que as experiências lúdicas e interativas, de aprendizagens significativas, no brincar, no interagir, no relacionar-se com outras crianças, adultos, objetos do mundo físico, ambiental e social, precisam valorizar as práticas culturais constitutivas de suas identidades sociais e coletivas. 
O Art. $8^{\circ}$ das DCNEI afirma que:

A proposta pedagógica das instituiçóes de Educação Infantil deve ter como objetivo garantir à criança acesso a processos de apropriação, renovaçáo e articulação de conhecimentos e aprendizagens de diferentes linguagens, assim como o direito à proteção, à saúde, à liberdade, à confiança, ao respeito, à dignidade, à brincadeira, à convivência e à interação com outras crianças (BRASIL, 2009, p. 2).

Percebemos que as crianças significam as brincadeiras de acordo com seus contextos. Elas se apropriam do mundo no qual vivem e constroem suas maneiras próprias de brincar. Nesse sentido, a escola, ao criar momentos em que a criança tem a liberdade de interagir e compartilhar seus mundos durante os processos de interaçóes, está promovendo uma educação que possibilita açóes livres e criadoras garantindo o direito à produção de conhecimentos articulados com diferentes linguagens.

A relação da criança do campo com o meio natural e social é um aspecto indissociável da prática educativa na escola. A escola campo de pesquisa atende a um público de realidades diferentes, de contextos socioculturais e econômicos distintos que se encontram cotidianamente na turma de educação infantil: a criança filha de trabalhadores(as) assentados(as) da reforma agrária; a criança filha de proprietários de grandes fazendas; e a criança filha do trabalhador assalariado de fazendas. Esse encontro nos permitiu analisar as significaçóes que esses sujeitos atribuem à educaçáo infantil do/no campo e nos colocou diante de um desafio inquietante e provocativo.

\section{REFERÊNCIAS}

ARROYO, M.G. Imagens quebradas: trajetórias e tempos de alunos e mestres. Petrópolis: Vozes, 2004.

ARENDT, H. A condição humana. Tradução de Roberto Raposo. Revisão técnica e apresentação de Adriano Correia. 12. ed. Rio de Janeiro: Forense Universitária, 2014. 
BARBOSA, M.C.S. (Org.). Oferta e demanda de educação infantil no campo. Porto Alegre: Evangraf, 2012.

BRASIL. Ministério da Educação. Câmara de Educação Básica do Conselho Nacional de Educação. Parecer CEB 022/98; Resolução CEB 1/1999. Diretrizes Curriculares Nacionais para a Educação Infantil. Brasília: MEC/SEF, 2009.

. Ministério da Educaçáo. Universidade Federal do Rio Grande do Sul. Caracterização das práticas educativas com crianças de 0 a 6 anos de idade residentes em áreas rurais. Brasília/Porto Alegre: MEC; UFRGS, 2012.

CALDART, R.S. Pedagogia do Movimento Sem-Terra. 3. ed. São Paulo: Expressão Popular, 2004.

FRANCO, C. A Escola da Criança Feliz: significaçôes da educação infantil dol no campo. Dissertação (Mestrado) - Universidade do Estado de Mato Grosso, Cáceres, 2016.

GOODSON, I. As politicas de currículo e de escolarização. Petrópolis: Vozes, 2008.

ROSSETTI-FERREIRA, M.C.; AMORIM, K.S.; SILVA, A.P.S.; CARVALHO, A.M.A. (Orgs.). Rede de significaçóes e o estudo do desenvolvimento humano. Porto Alegre: Artmed, 2004.

SILVA, A.P.S.; PASUCH, J. Orientaçôes Curriculares para a Educação Infantil do Campo. In: SEMINÁRIO NACIONAL CURRÍCULO EM MOVIMENTO: PERSPECTIVAS ATUAIS, 1., Belo Horizonte. Anais..., 2010.

SILVA, A.P.S.; PASUCH, J.; SILVA, J.B. Educação Infantil do Campo. São Paulo: Cortez, 2012.

\section{NOTAS}

1. Nova Mutum é um município criado em 1988 a partir de um projeto de ocupação da Colonizadora Mutum, identificado com a Integração Nacional. O processo de ocupação ocorreu no período em que o Governo Federal tinha como objetivo a ocupação do território considerado "vazio" na Região Norte do país, a expansão na América do Sul em direção ao Pacífico e ao Atlântico Sul e a formação de uma potência mundial. Hoje, o município possui cerca de 30 mil habitantes, segundo dados do site oficial da Prefeitura Municipal, e se destaca como um dos grandes produtores de soja, milho e algodão.

2. Assentamento rural localizado a $80 \mathrm{~km}$ da escola. 
3. Esta pesquisa foi desenvolvida por um grupo de pesquisadores organizado em cinco núcleos regionais: norte - Universidade Federal do Pará (UFPA); nordeste Universidade Federal de Campina Grande (UFCG); sudeste - Universidade Federal de Minas Gerais (UFMG); sul - Universidade Federal do Rio Grande do Sul (UFRGS); centro-oeste - Universidade Estadual de Mato Grosso (UNEMAT). Participaram ainda diferentes consultores especialistas, além de representantes do Movimento Interfóruns de Educação Infantil do Brasil (MIEIB), do Movimento dos Trabalhadores Rurais Sem Terra (MST) e da Confederação Nacional dos Trabalhadores na Agricultura (CONTAG).

4. Os nomes são fictícios para respeitar os critérios éticos de pesquisa.

5. A criança menciona o nome de uma empresa multinacional do agronegócio e alimentos, que comercializa e processa grãos como soja, trigo e milho.

Recebido em 20 de fevereiro de 2017.

Aprovado em 20 de junho de 2017. 